\title{
Using Rural Planning to Promote the Integration of Primary, Secondary and Tertiary Industries in Rural China
}

\author{
Jiawen $\mathrm{He}^{1, \text { a }}$ \\ ${ }^{1}$ School of Architecture and Urban Planning, Beijing University of Civil Engineering and Architecture, 1 Exhibition Hall Road, Xicheng \\ District, Beijing, 100044, PR China \\ aE-mail: 1660688344@qq.com
}

\begin{abstract}
Rural planning plays an important role in rural industrial integration, but there are few researches on the planning methods of rural industrial integration in China at present. Therefore, learning from the successful experience of developed countries and combining with the current situation of rural economic and social development in China is an important means and basic idea to explore the rural planning method of guiding the integration of primary, secondary and tertiary production in rural areas in China.
\end{abstract}

Keywords: Rural Revitalization, Industrial Integration, Rural Planning; Industrial System, Land Use System.

\section{Introduction}

In recent years, China's agriculture and rural economy have developed rapidly and steadily, and farmers' income has been greatly increased. At the same time, the deep-seated contradictions accumulated by long-term extensive management have gradually emerged, resulting in severe challenges such as rising agricultural development costs, deteriorating ecological environment and tight resource conditions. In 2014, the Central Rural Work Conference proposed that modern industrial organization methods such as industrial chain and value chain should be introduced into agriculture, and for the first time, it explicitly requested to promote the integration and interaction of primary, secondary and tertiary industries [1], and put the promotion of the integration and development of primary, secondary and tertiary industries in rural areas into the Central Document No.1 in 2015 and 2016 [2-3]. In January 2016, the State Council issued the Guiding Opinions of the General Office of the State Council on Promoting the Integration Development of Rural Primary, Secondary and Tertiary Industries, which put forward the guiding ideology, basic principles and main objectives of promoting the integration development of rural primary, secondary and tertiary industries, and put forward detailed paths for the integration development of rural garment secondary and tertiary industries, such as multi-type rural industrial integration methods, cultivating diversified rural industrial integration subjects, establishing multi-form interest linkage mechanism, perfecting multi-channel rural industrial integration services and improving rural industrial integration promotion mechanism [4]. From 2017 to 2021, the "No.1 Document" of the Central Committee made detailed arrangements for the integration and development of rural primary, secondary and tertiary industries, including the construction of a modern agricultural industrial park of "production + processing + technology", vigorously developing the rural leisure tourism industry, and promoting agriculture, forestry and tourism. Deep integration of industries such as education, culture and health care, cultivating characteristic villages and towns with deep integration of livable and suitable industries [5], focusing on supporting rural leisure tourism and pension industries and rural tertiary industries Construct a rural one, two and three industries integration development system [6]; Improve the interest linkage mechanism for the integration and development of rural primary, secondary and tertiary industries [7]; Support all localities to build the entire agricultural industrial chain based on resource advantages, establish and improve the mechanism for farmers to share the value-added benefits of the industrial chain, form a competitive industrial cluster, and issue policy opinions to support the integration and development of rural primary, secondary and tertiary industries [8]; Promote the construction of demonstration parks and science and technology demonstration parks for the integration and development of primary, secondary and tertiary industries in rural areas, develop smart agriculture and establish a big data system for agriculture and rural areas, and promote the deep integration of information technology and agricultural production and management [9].

Under the background that China's economic development enters a new normal, the integration of rural primary, secondary and tertiary industries is an important measure put forward by the state to further accelerate the development of agricultural modernization. It has distinct characteristics of the times and important theoretical and practical significance: (1) It is conducive to stimulating the vitality of agriculture, rural areas and farmers, extending the agricultural industrial chain, enriching the types of rural industries, increasing the added value of agricultural products, improving the overall efficiency of agriculture, and broadening the channels for increasing farmers' income [10]. (2) It is conducive to tapping the new potential of rural development, enhancing rural attractiveness, enhancing rural competitiveness, promoting the return of talents, and promoting the construction of beautiful countryside, rich villages and dynamic villages [11]. (3) It is conducive to the rational two-way flow of capital, talents, information and products between urban and rural areas, and reshape the relationship between urban and rural areas [12]. (4) Conducive to ecological environment 
protection and governance.

\section{Literature Review}

\subsection{Research Progress of Foreign Rural Industrial Integration Development}

Foreign studies on industrial integration mostly focus on secondary and tertiary industries and their internal integration, but lack of studies on agriculture and its integration with secondary and tertiary industries. At the end of 1990s, Japanese agricultural expert Nara Imamura put forward "six industrialization", which basically means that agricultural production extends to the secondary and tertiary industries, forming a complete industrial chain integrating production, processing, sales and service, marking that agriculture has been formally incorporated into the research field of industrial integration [13]. South Korea learns from Japan's "Six Industrializations", and through deep integration of agriculture and secondary and tertiary industries, makes agriculture go beyond the traditional field of pure agricultural products production, uses local manpower and natural resources, integrates advanced creativity and technology, opens up new markets and provides new jobs by means of innovation and integration, increases the added value of agricultural products, and revitalizes local agriculture to stimulate rural vitality [14]. The American agricultural system is called "agribusiness". On the one hand, it takes agribusiness as an entity to realize vertical integration of agricultural industry, on the other hand, it forms a new industrial form through horizontal integration of agricultural industry. The United States introduced the mature management methods and experience of the industrial sector into agriculture, formed the integration of production, processing and sales, and realized industrial operation. For example, the video production and marketing system formed a complete system of "from field to table" [15]. The Netherlands has built an efficient agricultural industrial chain, built industrial clusters, developed creative agricultural industries, increased the added value of agricultural products, and built a dynamic "new countryside", and spontaneously established a mutually beneficial and win-win agricultural cooperation model, promoted scientific research, education and extension systems, and established a highly developed agricultural knowledge innovation system [16]. Through combing and analyzing the research on foreign rural industrial integration, it is found that the commonness of developed countries' experiences and practices is to always put farmers' interests first, give full play to the role of agricultural associations, pay attention to farmers' skills training, and provide supporting services such as laws and subsidies.

\subsection{Research Progress of Domestic Rural Industrial Integration Development}

The research on the integration of the three industries in China originated in 1980s. Some scholars believe that the connection between agriculture and industry is not close at that time, which mainly relies on manpower and simple primitive tools to develop agriculture, which limits the largescale development of agriculture. Agricultural industrialization can promote the rapid development of township enterprises, so it is necessary to promote agricultural industrialization [17]. In 1997, Yu Lingang first pointed out the phenomenon of the integration of primary, secondary and tertiary industries, and systematically put forward the theory of industrial integration [18]. After that, the research of Chinese scholars mostly focused on the connotation and significance, development model, evaluation methods and other aspects of the integration of rural tertiary industry [19-21]. Among them, there are many development models of the integration of rural tertiary industry, which can be divided into three types according to the main business entities: rural cooperative-oriented (cooperative + farmer), "enterprise + farmer" combined type, and "enterprise + farmer + cooperative" compound type [22]. There are various integration modes of "agriculture + tourism", among which the common modes are farmhouse music and rural tourism [23]. The development of rural tourism has promoted industrial integration, and at the same time, the rural economy will develop rapidly. However, while developing rural tourism, we should create new features, attract investment, improve farmers' quality, improve infrastructure, and use the network to broaden rural tourism operation channels [24]. At present, the research on the connotation, characteristics and mode of rural industrial integration development in China has a certain theoretical basis, but it still focuses on summing up, introducing experience and extending interpretation, and has not formed a systematic research framework, especially lacks research on planning methods and paths of rural industrial integration development.

\section{Elaboration of Key Planning Methods}

The integration development of rural primary, secondary and tertiary industries involves not only the political, economic and social development in rural areas, but also the ecological security, environmental security and food security in rural areas. Therefore, rural planning is one of the important ways for the integration development of rural primary, secondary and tertiary industries. Rural planning is the comprehensive deployment, specific arrangement and implementation management of rural economic and social development, land use and various constructions in a certain period [25]. Based on the requirements and deployment of "Document No.1" over the years in China, combined with the research progress of domestic agricultural industry integration, and drawing lessons from the successful experiences and practices of foreign developed countries, the formulation of rural planning can promote the integration development process of primary, secondary and tertiary industries in rural areas through six methods, such as current situation survey, project planning, industrial system construction, spatial planning, land system innovation and implementation and operation.

\subsection{Survey the Current Situation and Find Out the Detail Background}

Rural planning, which aims to promote the integration of primary, secondary and tertiary industries in rural areas, should pay attention to preliminary investigation, and use a variety of survey and exploration methods to conduct a general survey of various rural resources. Pay attention to villagers' participation and villagers' wishes. On the basis of in-depth investigation and general survey of natural and cultural resources, fully grasp the current situation information of rural natural environment, political economy, social culture, etc., and provide the basis for scientific planning. In-depth research and census methods are mainly 
divided into traditional research methods and big data research methods, among which traditional research methods include data collection, questionnaire survey, household interview, drawing marking, image shooting, villagers' symposium, field survey, etc. [25]; Research methods of big data include web search, hot word search, database construction and so on. The research mainly involves the basic situation of villages, regional environment, village history and humanities, village natural environment, village industrial status, village population, village infrastructure, village style, network public opinion and so on.

\subsection{Project Planning and Potential Assessment}

Actively respond to the No.1 Document of the Central Committee over the years, find out the village's own characteristics and analyze the rural development potential based on the general survey of the current situation of villages and the advantages of local resources. On the basis of in-depth investigation, through the analysis of market demand, regional conditions, development trend and various resources, starting from its own advantages, it scientifically puts forward the industrial orientation, clarifies the industrial chain extension, industrial upgrading path and industrial integration mode, and further carries out in-depth project planning and product design, and puts forward the direction and strategy of rural development. In view of the opportunity of the integration and development of rural primary, secondary and tertiary industries, we plan how to introduce social capital and social intelligence, determine multiple participants, coordinate with villagers, government, investors, planners and so on and negotiate and plan together to promote the construction process. Establish a good operation mode and income-generating and return mechanism, transform the development concept into projects, products and action plans, and prepare detailed industrial planning and spatial planning based on the planning scheme [26].

\subsection{Industrial Planning and System Construction}

Rely on the planning scheme to determine the rural industrial integration mode, and build different primary, secondary and tertiary industrial integration systems according to different leading modes. The industrial integration model dominated by primary production usually extends the industrial chain through the development of secondary industries such as agricultural product processing and traditional manual production, and the intervention of industrial services and leisure services in $\mathrm{R} \& \mathrm{D}$, production and marketing [27]; The industrial integration development model led by the secondary processing industry, relying on the deep processing and manual manufacturing of agricultural products and special skills, realizes the high integration of agriculture, cultural creation and tourism, and realizes the inheritance of culture and skills; The development mode of industrial integration led by the tertiary industry includes consumption-driven integration led by tourism and cultural creativity as the core [28]. Then build a specific industrial system and build the whole agricultural industrial chain. On the one hand, enhance the added value of agricultural products and reshape the agricultural value; on the other hand, expand industrial functions, and derive new industries and new formats with diversified and compound functions to form competitive industrial clusters.

\subsection{Spatial Planning and Implementation of Layout}

Implement industrial system planning and project planning in rural space through spatial planning and design. The content mainly includes the overall spatial layout, industrial spatial layout, supporting infrastructure, construction of public service facilities, village landscape planning, spatial node design, etc. [29]. It is worth noting that the industrial spatial layout should make full use of the current rural industry, maximize its efficiency, respect the morphological characteristics of villages, not destroy the rural spatial form due to industrial development, protect historical humanities, not destroy village culture, cherish natural environmental resources, not develop industries at the expense of the environment, avoid mutual interference between production space and living space, and create a good living and production space [30]. In terms of methods, planners should play the role of "media", take villagers as the main body, put the needs of villagers at the core position, let villagers participate in spatial planning and design, and fully solicit opinions from local governments and social capital to achieve multi-party recognition and make the industrial system land.

\subsection{Institutional Innovation and Land Activation}

Actively implement the requirements of Document No.1 of the Central Committee in 2017 and 2020, and explore the innovation of rural land system as the material basis for the integration and development of rural primary, secondary and tertiary industries. Explore the rural land "separation of powers" reform, improve the land use mechanism, actively explore the implementation of the collective ownership of homestead, protect the homestead farmers' qualification rights and farmers' housing property rights, moderately release the specific paths and methods of homestead and farmers' housing use rights, and steadily carry out the idle homestead and idle housing revitalization and utilization pilot [31]. The establishment of rural collective construction land listing mechanism, allowing rural collective construction land transfer, lease, shares, the implementation of the same market with state-owned land, the same rights and prices [9]. Strengthen the construction of rural property rights transfer market. Will be traded in accordance with the law of rural land contractual management rights, rural collective management of construction land use rights, rural collective management assets and other tradable rural property rights into the unified circulation trading platform.

\subsection{Implement Operation and Benefit Sharing}

Rural planning with the goal of promoting the integration of primary, secondary and tertiary industries in rural areas should guarantee the implementation and operation of the planning, establish and improve the mechanism for farmers and other stakeholders to share the value-added benefits of the industrial chain, and coordinate and clarify the rights, responsibilities and interests of villagers, governments, social capital and planners. We should build a new rural system, absorb new population by industrial integration, industrial upgrading and industrial agglomeration, and form a new talent support system, including rural aborigines, secondgeneration farmers returning home, new professional farmers upgrading agricultural industry, "feeling villagers" and "returning villagers" who return home to start businesses. 
Improve the rural governance system, strengthen the coconstruction, sharing and co-governance of the integration and development of primary, secondary and tertiary industries in rural areas.

\section{Conclusion}

At present, China has entered an important period of accelerating the development of rural modernization. In rural planning, we should promote the integration of primary, secondary and tertiary industries in rural areas, implement well in preliminary investigation, project planning, industrial development system construction, falling into physical space, exploring land reform and strengthening operational guarantee. Realize the mutual support, interdependence and integrated development of the primary, secondary and tertiary industries, achieve the goal effect of co-construction and winwin.

\section{References}

[1] Zong Jinyao. the theory and practice of the integration of rural primary, secondary and tertiary industries [M]. Beijing: China agriculture press, 2017.

[2] People's Government of the People's Republic of China. Opinions of the CPC Central Committee and the State Council on Intensifying Reform and Innovation and Accelerating Agricultural Modernization [Z]. http://www.gov.cn/zhengce/2015-02/01/content_2813034.htm

[3] People's Government of the People's Republic of China. Opinions of the Central Committee of the Communist Party of China and the State Council on Implementing the New Concept of Development and Accelerating Agricultural Modernization to Achieve the Goal of a Well-off Society in an All-round Way [Z]. 01/27/content 5036698.htm http://www.gov.cn/zhengce/2016-

[4] General Office of the State Council of the People's Republic of China. Guiding Opinions on Promoting the Integration and Development of Rural Primary, Secondary and Tertiary Industries [Z]. http://www.gov.cn/zhengce/content/201601/04/content 10549.htm

[5] People's Government of the People's Republic of China. Opinions of the CPC Central Committee and the State Council on Deepening the Structural Reform of the Supply Side of Agriculture and Accelerating the Cultivation of New Kinetic Energy for Agricultural and Rural Development [Z]. 5626.htm, http://www.gov.cn/zhengce/2017-02/05/content 516

[6] People's Government of the People's Republic of China. Opinions of the CPC Central Committee and the State Council on Implementing the Strategy of Rural Revitalization [Z]. http://www.gov.cn/zhengce/2018-02/04/content_5263807.htm

[7] People's Government of the People's Republic of China. Opinions of the CPC Central Committee and the State Council on Adhering to the Priority Development of Agriculture and Rural Areas and Doing a Good Job in "Agriculture, Rural Areas and Farmers" [Z]. http://www.gov.cn/zhengce/201902/19/content 5366917.htm

[8] People's Government of the People's Republic of China. Opinions of the Central Committee of the Communist Party of China and the State Council on focusing on the "three rural" areas to ensure the timely realization of a comprehensive welloff society [Z]. http://www.gov.cn/zhengce/202002/05/content_5474884.htm

[9] People's Government of the People's Republic of China. Opinions of the CPC Central Committee and the State Council on comprehensively promoting rural revitalization and accelerating agricultural and rural modernization [Z]. http://www.moa.gov.cn/xw/zwdt/202102/t20210221 6361863 .htm

[10] Su Yiqing, You Yuting, Wang Zhigang. Integration and development of primary, secondary and tertiary industries in rural areas: theoretical discussion, current situation analysis and countermeasures [J]. China Soft Science, 2016(8): 17-28.

[11] Huang yuanbin, Li qiyu. research on innovation and application of rural tertiary industry integration mode under rural revitalization strategy-based on the perspective of regional economics $[\mathrm{J}]$. rural economy and science and technology, 2020, 31(9): 15-17.

[12] Ning Zhizhong, Zhang Qi. The flow and optimal allocation of urban and rural elements under the background of rural priority development [J]. Geography Research, 2020, 39(10): 22012213.

[13] Chen Xi, Ou Xiaoming, Han Jiangbo. Operation Ecology of "Sixth Industry": Logical Mechanism and New Thinking of Governance — Japanese Case and Enlightenment from China [J]. Economic System Reform, 2018(3): 153-159.

[14] Cheng Chengping, Xie xueke. main practices and enlightenment of developing the sixth industry in Japan and south Korea [J]. economic aspect, 2016(8): 114-118.

[15] Dai Xiaoti. American agricultural development experience and enlightenment from the perspective of multi-industry integration $[\mathrm{J}]$. Beijing agriculture, 2013(32): 26-31.

[16] Zhao Xia, Jiang Lina. Enlightenment of developing modern agriculture in the Netherlands on promoting the integration of primary, secondary and tertiary industries in rural China $[\mathrm{J}]$. World Agriculture, 2016(11): 21-24.

[17] Gu Yikang. rural industrialization must keep pace with agricultural intensification $[\mathrm{J}]$. agricultural economic problems, 1985(8):7-10

[18] Yu Rengang. the trend of three industrial classifications and industrial integration $[\mathrm{J}]$. economic research reference, 1997(25): 46-47.

[19] Ma Jian. review of industrial integration theory [J]. economic trends, 2002(5): 78-81.

[20] Liu hongna, yang tongyi. research on evaluation index system of integration of three industries [J]. rural economy and science and technology, 2018(17): 54-56.

[21] Jin Yining, Ye Lirun. A summary of the research on the integration of rural tertiary industry in China [J]. China Collective Economy, 2020(7): 3-5.

[22] Zhang Tianyu. Study on the organizational model of rural "integration of three industries" [D]. Central China Normal University, 2017.

[23] Yang Zhenzhi. integration and development of agricultural industry and rural tourism under urban and rural planning $[\mathrm{J}]$. journal of tourism, 2011(10): 10-11.

[24] Hou Yujie, Ma Liqing. rural tourism development model under the background of new countryside $[\mathrm{J}]$. rural economy and technology, 2018(14): 74-75.

[25] Ning Zhizhong editor. Rural Geography of China [M]. Beijing: China Building Industry Press, 2019.

[26] Wu Mingming. a preliminary study of rural planning methods in Yunnan in the new era-taking bapai village, hehua town, Tengchong as an example [D]. Kunming university of science and technology, 2018.

[27] Zong jinyao. promoting the integration and development of primary, secondary and tertiary industries in rural areas under the guidance of agricultural products processing industry [J]. agricultural engineering technology: agricultural products processing industry, 2015(13): 19-22. 
[28] Institute of High-tech Industrial Economics. How to solve the problem of industrial integration and development in rural revitalization planning [db/ol]. http://www.achie.org/ news/cygh/2019/0626/7603.html

[29] Gaomi. A preliminary study of rural planning methods based on the perspective of industrial restructuring — Taking the planning of "three townships" in Nanchuan District of Chongqing as an example [D]. Chongqing University, 2012.
[30] Niu Shujun. Research on the Innovation of Rural Planning Methods in Underdeveloped Areas under the Guidance of "Rural Revitalization" —_ Taking the Planning of Chugutuan Rural Revitalization Demonstration Zone in Yangyuan County as an example [D]. Hebei Institute of Architecture and Engineering, 2019.

[31] Sun Xianzhong. Promote the legislative research on the business model of separation of the three powers of agricultural land [J]. China Social Sciences, 2016(7): 145-163. 